\title{
The Sensitivity of Long-Term Interest Rates to Economic News: Evidence and Implications for Macroeconomic Models
}

\author{
By Refet S. GÜrkaynak, Brian Sack, and ERIC Swanson*
}

Current macroeconomic models provide appealing, succinct descriptions of business cycle dynamics in the United States and other countries, but less is known about the extent to which these models accurately replicate the economy's long-run characteristics. In part, this reflects that economists have far fewer observations about long-run behavior, given the limited sample sizes available. But while less is known about the long-run characteristics of the economy, many macroeconomic models impose very strong assumptions about this behaviorthat the long-run levels of inflation and the real interest rate are constant over time and perfectly known by all economic agents. This paper empirically tests those assumptions and proposes alternative ones.

Specifically, we focus on the effects of macroeconomic and monetary policy surprises on the term structure of interest rates. In many standard macroeconomic models, short-term interest rates tend to return relatively quickly to a deterministic steady state after a macroeco-

\footnotetext{
* Gürkaynak: Division of Monetary Affairs, Federal Reserve Board, and Department of Economics, Bilkent University, 06800 Ankara, Turkey (e-mail: refet@bilkent.edu. tr); Sack: Macroeconomic Advisers, LLC, 1776 I St., NW, Washington, DC 20006 (e-mail: bsack@macroadvisers. com); Swanson: Division of Monetary Affairs, Federal Reserve Board, Washington, DC 20551 (e-mail: eswanson@ frb.gov). This paper was written while all authors were at the Federal Reserve Board. The opinions expressed are those of the authors and do not necessarily reflect the views of the Board of Governors or other members of its staff. We thank two anonymous referees, Richard Rogerson (the coeditor), Geert Bekaert, Qiang Dai, Sharon Kozicki, Ken Kuttner, Tao Wu, and seminar participants at the Federal Reserve Board, the University of Virginia, the StanfordFRBSF Conference on Finance and Macroeconomics, the NBER Summer Institute, the Bank of England, the 2003 EES/EM Conference, and the 2004 AEA Meetings for helpful comments and suggestions. Emily Cauble provided excellent research assistance.
}

nomic or monetary policy shock, so that these shocks have only transitory effects on the future path of interest rates. As a result, one would expect only a limited response of long-term interest rates to these disturbances. Putting this prediction in terms of forward rates, one would expect virtually no reaction of far-ahead forward rates to such shocks.

The behavior of the U.S. yield curve appears, however, to contrast sharply with these predictions. In particular, we demonstrate that longterm forward rates move significantly in response to the unexpected components of many macroeconomic data releases and monetary policy announcements. We interpret these findings as indicating that an assumption made in these models - that the long-run expectations of economic agents are precise and time-invariant-is violated. In particular, our empirical results are all consistent with a model that we present in which private agents' views of long-run inflation are not strongly anchored.

\section{Long-Run Implications of Macroeconomic Models}

Many of the models commonly used in the macroeconomics literature assume that the long-run characteristics of the economy, such as the levels of inflation and the real interest rate, are constant over time and perfectly known by all economic agents. An implication of this assumption is that, after a macroeconomic or monetary policy shock, expectations of shortterm nominal interest rates far enough in the future should remain relatively fixed.

To illustrate this effect, we focus on two standard macroeconomic models: a pure "New Keynesian" model (taken from Richard Clarida et al., 2000) and a modification of that model that allows for a significant fraction of "backward-looking" or "rule of thumb" agents 
(taken from Glenn Rudebusch, 2001). These two models can be summarized by the following equations:

$$
\begin{aligned}
\pi_{t}= & \mu E_{t} \pi_{t+1}+(1-\mu) A_{\pi}(L) \pi_{t} \\
& +\gamma y_{t}+\varepsilon_{t}^{\pi} \\
y_{t}= & \mu E_{t} y_{t+1}+(1-\mu) A_{y}(L) y_{t} \\
& -\beta\left(i_{t}-E_{t} \pi_{t+1}\right)+\varepsilon_{t}^{y}
\end{aligned}
$$

where $\pi$ denotes the inflation rate, $y$ the output gap, $i$ the short-term nominal interest rate, and $\varepsilon^{\pi}$ and $\varepsilon^{y}$ are i.i.d. shocks. The parameter $\mu$ denotes the degree of forward-looking behavior in the model, and the lag polynomials $A_{\pi}(L)$ and $A_{y}(L)$ summarize the parameters governing the dynamics of any backward-looking components of the model.

The two models considered differ in the extent of their forward-looking behavior. In the pure New Keynesian model, we assume that agents are completely forward-looking, or $\mu=$ 1 , and we take the parameter values for the equations from Clarida et al., (2000). However, much smaller values of $\mu$ (around 0.3 ) have been estimated and advocated by Jeffrey C. Fuhrer (1997), John M. Roberts (1997), Rudebusch (2001), and Arturo Estrella and Fuhrer (2002) to match the degree of persistence in U.S. data. Thus, in the second model considered, we set $\mu=0.3$ and take parameter values from Rudebusch (2001). ${ }^{1}$

We close these two models with an interest rate rule of the form:

$$
\begin{aligned}
i_{t}= & (1-c)\left[\bar{\pi}_{t}+a\left(\bar{\pi}_{t}-\pi^{*}\right)+b y_{t}\right] \\
& +c i_{t-1}+\varepsilon_{t}^{i}
\end{aligned}
$$

where $\bar{\pi}$ denotes the trailing four-quarter moving average of inflation, $\pi^{*}$ is a constant inflation target, $\varepsilon^{i}$ is an i.i.d. shock, and $a, b$, and $c$

\footnotetext{
${ }^{1}$ Rudebusch estimates and uses a value of $\mu=0.29$, so we use that value as well. There are also some minor timing differences between equations (1) and (2) and the specification of Rudebusch's model. To generate the impulse response functions in Figure 1, we use the model exactly as specified in Rudebusch (2001), but these differences in specification have no discernible effect on our results.
}

are the parameters of the rule. ${ }^{2}$ Note that the policy rule is both "backward-looking," in that the interest rate responds to current values of the output gap and inflation rather than their forecasts, and "inertial," in that it includes the lagged federal funds rate. Both of these characteristics tend to add persistence to the short rate, which generally gives these models the best possible chance to explain the term structure evidence we find below. We include an interest rate shock $\varepsilon_{t}^{i}$ for the purpose of generating impulse response functions.

The three panels of Figure 1 show the response of the short-term nominal interest rate to a 1-percent shock to the inflation equation, the output equation, and the interest rate equation, respectively, under our two baseline models. In the pure New Keynesian (CGG) model, depicted by the solid lines, the effect of the macroeconomic and monetary policy shocks on the short-term interest rate dies out very quickly, generally within a year. The interest rate displays much more persistence in the partially backward-looking (Rudebusch) model, depicted by the dashed lines. But even in that model, the short-term interest rate essentially returns to its steady-state level well within ten years of each shock. We now turn to how well these predictions are matched by the data.

\section{The Sensitivity of Long-Term Interest Rates}

Because the short-term interest rate returns to its steady-state value fairly quickly in the two models above, expectations of short-term interest rates at longer horizons should be well anchored. This section investigates whether this prediction is consistent with the behavior of the term structure of interest rates. It is perhaps easiest to think of the term structure implications of the models in terms of forward rates rather than yields. A yield represents the return that an investor demands to lend money today in return for a single payment in the future (in the case of a zero-coupon bond). A forward rate, instead, represents the rate of return that an investor would demand today to commit to lending money, say, nine years ahead for a

\footnotetext{
${ }^{2}$ We set $\mathrm{a}=0.53, \mathrm{~b}=0.93$, and $\mathrm{c}=0.73$, as estimated by Rudebusch (2002) for the period 1987Q4-1999Q4.
} 
Interest Rate Response to a 1 percent Inflation Shock
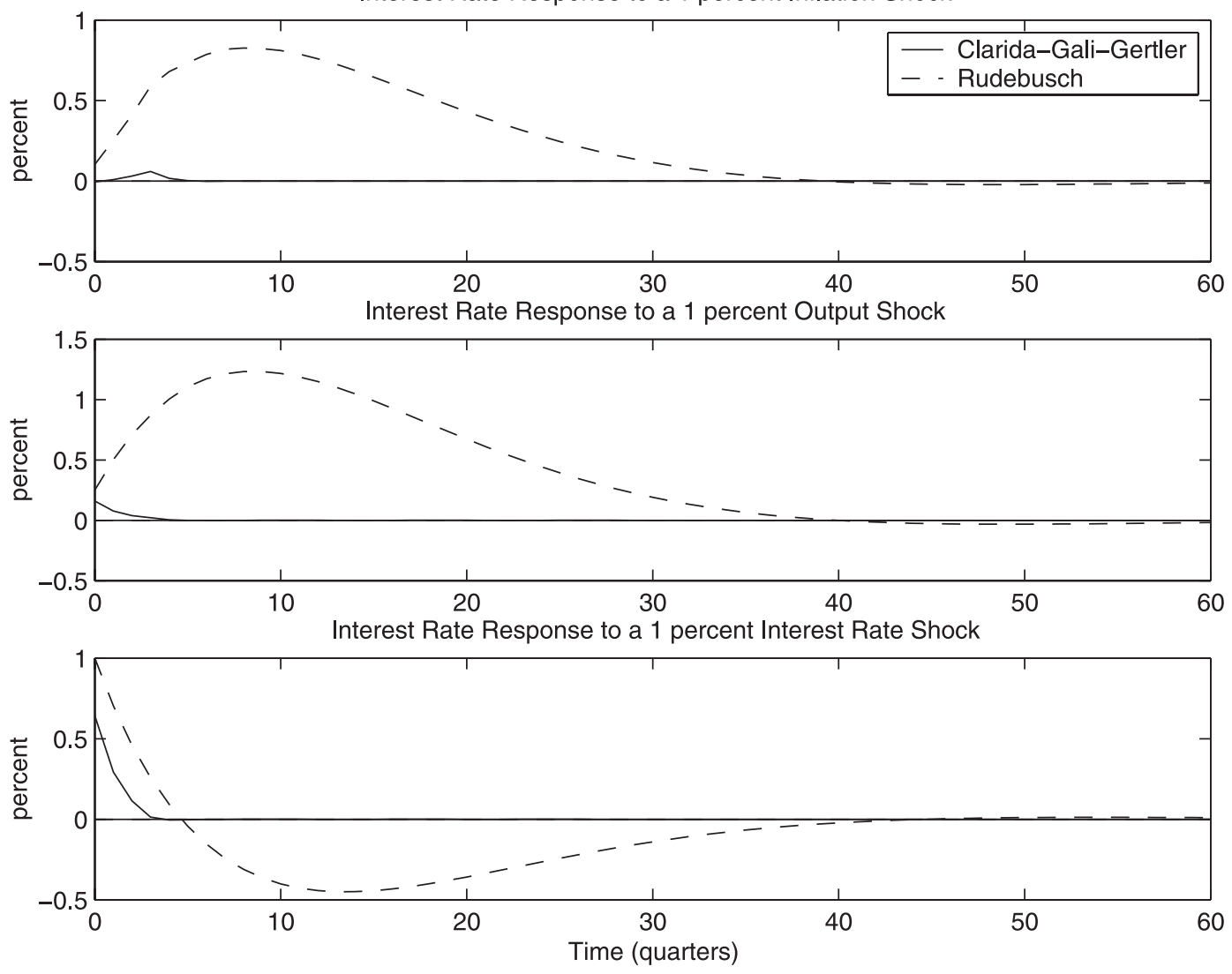

Figure 1. Impulse Response Functions for Standard Macro Models

payment ten years ahead. The linkage between these concepts is simple: a ten-year zero-coupon security can be thought of as a string of forwardrate agreements to lend money for one-year periods today, in one year, in two years, and so on up to nine years.

For our analysis, we use data on U.S. Treasury forward rates obtained from the Federal Reserve Board; these data are computed from U.S. Treasury yields using the method of Lars E. O. Svensson (1994). ${ }^{3}$ The working paper

\footnotetext{
${ }^{3}$ This procedure is relatively straightforward: the Svensson zero-coupon yield curve is estimated through off-therun Treasury notes and bonds, taking into account the coupon payments and somewhat irregular maturity dates of these securities; this smoothed zero-coupon yield curve then implies a set of forward rates.
}

version of this article (Gürkaynak et al., 2003) shows that the findings presented below are robust to measuring forward rates from Treasury Separate Trading of Registered Interest and Principal of Securities (STRIPS) yields (which does not require smoothing a yield curve first), as well as to changes in the sample period and the treatment of outliers.

\section{A. The Sensitivity of Long-Term Interest Rates to Macroeconomic News}

In Table 1, we regress daily changes in forward rates on the surprise component of macroeconomic data releases and monetary policy announcements. The surprise component of each macroeconomic data release is computed as the released value less the market expectation, 
Table 1-Responses of Forward Rates to Economic News

\begin{tabular}{|c|c|c|c|c|c|c|}
\hline & \multicolumn{2}{|c|}{ Ending 1 yr. ahead } & \multicolumn{2}{|c|}{ Ending 5 yrs. ahead } & \multicolumn{2}{|c|}{ Ending 10 yrs. ahead } \\
\hline & Coef. & Std. Err. & Coef. & Std. Err. & Coef. & Std. Err. \\
\hline \multicolumn{7}{|l|}{ Macroeconomic data releases } \\
\hline Capacity utilization & 1.36 & $0.33^{* * *}$ & 1.26 & $0.57 * *$ & 0.80 & 0.61 \\
\hline Consumer confidence & 2.11 & $0.40 * * *$ & 2.88 & $0.56 * * *$ & 1.97 & $0.54 * * *$ \\
\hline CPI (core) & 1.67 & $0.42 * * *$ & 1.81 & $0.60 * * *$ & 1.09 & $0.66 *$ \\
\hline Employment cost index & 3.43 & $0.89 * * *$ & 4.42 & $1.13^{* * *}$ & 3.73 & $0.93 * * *$ \\
\hline GDP (advance) & 4.39 & $1.42 * * *$ & 4.12 & $2.19^{*}$ & 3.76 & $1.82 * *$ \\
\hline Initial claims & -0.83 & $0.24 * * *$ & -0.79 & $0.29 * * *$ & -0.59 & $0.27 * *$ \\
\hline Leading indicators & 0.95 & $0.34 * * *$ & 0.61 & 0.57 & 0.55 & 0.58 \\
\hline NAPM & 3.00 & $0.51 * * *$ & 3.29 & $0.54 * * *$ & 1.53 & $0.63 * *$ \\
\hline New home sales & 1.08 & $0.39 * * *$ & 1.65 & $0.54 * * *$ & 0.92 & $0.51 *$ \\
\hline Non-farm payrolls & 5.10 & $0.57 * * *$ & 3.48 & $0.91 * * *$ & 1.88 & $0.97 *$ \\
\hline PPI (core) & 0.39 & 0.45 & 1.22 & $0.56^{* *}$ & 1.46 & $0.50 * * *$ \\
\hline Retail sales & 2.97 & $0.72 * * *$ & 2.62 & $1.03 * *$ & 1.93 & $0.92 * *$ \\
\hline Unemployment rate & -1.76 & $0.51 * * *$ & -0.77 & 0.73 & 0.14 & 0.66 \\
\hline Monetary policy surprises & 0.47 & $0.10^{* * *}$ & -0.04 & 0.14 & -0.16 & $0.07 * *$ \\
\hline
\end{tabular}

Notes: Huber-White standard errors. *** indicates significance at the 1-percent level, ** at the 5-percent level, and * at the 10-percent level. The estimated coefficient indicates the basis-point response of the one-year forward rate per standard deviation of the macroeconomic variable and per-basis-point surprise in monetary policy announcement. Regressions include constant terms that are not shown in the table.

where we measure market expectations using the median market forecast as compiled and published by Money Market Services the Friday before each release. We divide each macroeconomic surprise series by its standard error to make the regression coefficients easily interpretable as the effect of a one-standard-error surprise in that release. Our sample consists of all business days from January 1990 through December 2002, although there is some variation across statistics in the period for which MMS data are available. ${ }^{4}$ The measurement of monetary policy surprises and their effects are discussed in detail below.

We include in the regression all macroeconomic data releases that significantly affect the spot one-year Treasury yield (i.e., the one-year forward rate ending one year ahead) over our sample. ${ }^{5}$ As can be seen in the first column of

\footnotetext{
${ }^{4}$ Note that for any given macroeconomic statistic, the daily time series of surprises is mostly zeros, since each statistic is typically released only once per month (or in some cases once per quarter).

${ }^{5}$ This leaves us with 13 macroeconomic data releases out of a total of 39 for which we had MMS data. We obtained a very similar set of releases using other criteria, such as those releases that lead to the biggest increase in stock market trading volume (Michael Fleming and Eli Remolona, 1997). We also included the core PPI release in
}

Table 1, when releases that are pro-cyclical (such as retail sales) have a higher realized value than expected, the short-term interest rate increases, and when countercyclical indicators (such as initial claims) turn out to be higher than expected, the one-year yield responds negatively. Similarly, data releases that pertain directly to near-term inflation (such as the consumer price index) lead interest rates to respond in the same direction as the surprise. These responses are all consistent with the predictions of standard monetary policy reaction functions, such as a Taylor rule.

Of greater relevance to the current paper, though, is the fact that many of these variables also have a significant impact on one-year forward rates ending five and even ten years ahead. Eleven out of the 13 variables enter the regressions with significant coefficients (at the 10percent level) for the five-year-ahead forward interest rate, and ten variables enter significantly for the ten-year-ahead forward interest rate. This sensitivity of long rates is present both for indicators of inflation (e.g., the core

our regressions for this reason, and because it seems to have a significant effect at longer horizons. Our results are very similar when we include all 39 data releases in the regression. 


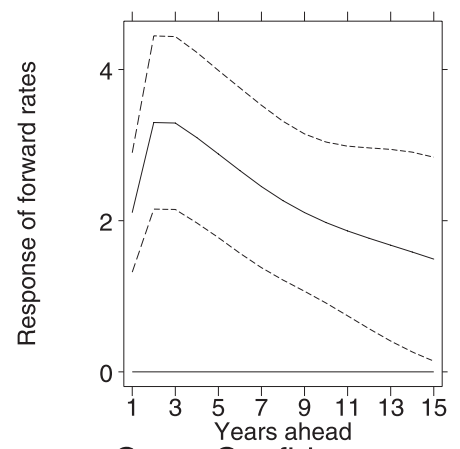

Cons. Confidence
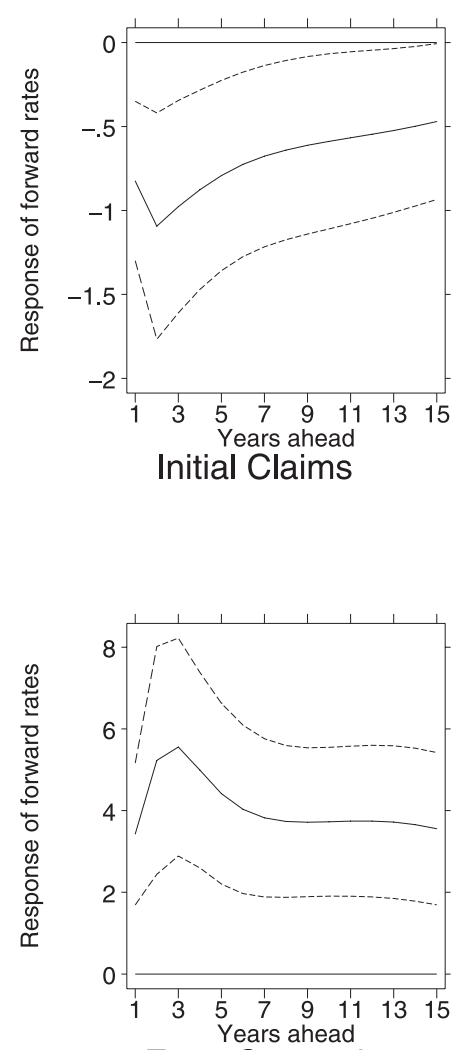

Emp. Cost Ind.

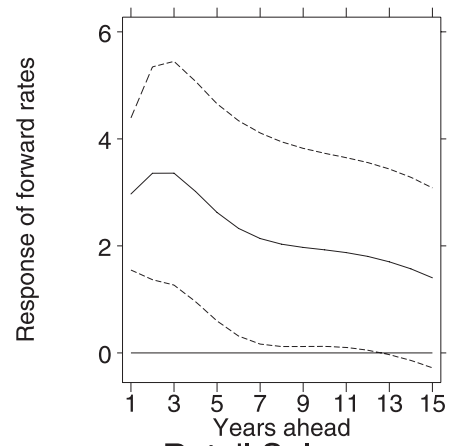

Retail Sales
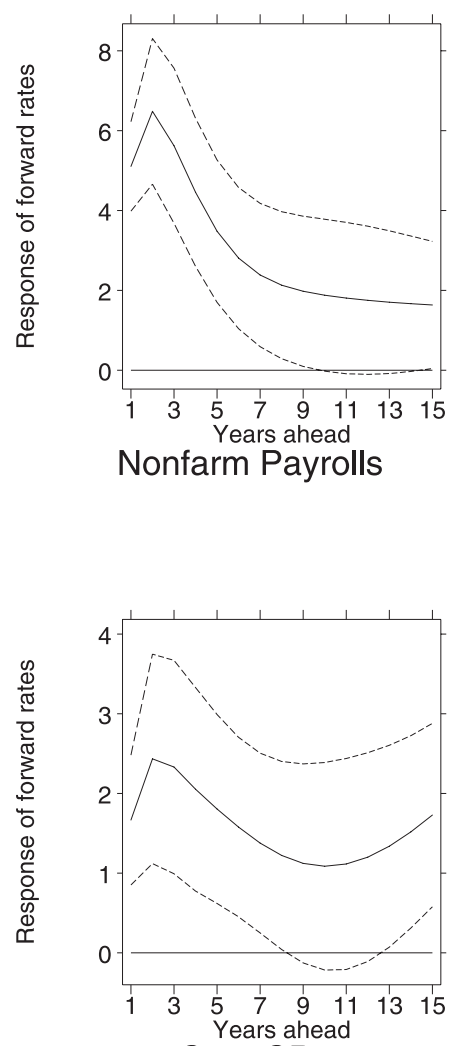

Core CPI
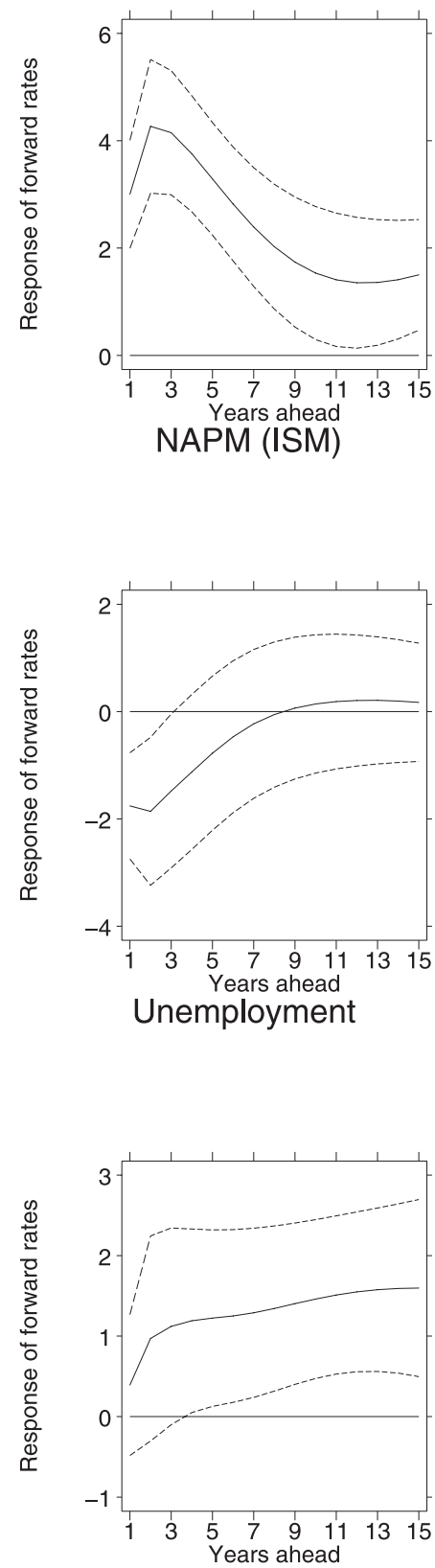

Core PPI

Figure 2. Response of Forward Rates to Macroeconomic Surprises

producer price index and the employment cost index) and for indicators of output (e.g., GDP, non-farm payrolls, and retail sales). Moreover, in many cases the response of the long-term forward interest rate is only modestly smaller than the response of the spot one-year rate.

In Figure 2, we present the same results graphically for nine of the data releases. In each 
panel of the figure, we plot the regression coefficients for the response of the one-year forward rate at horizons ending from one to 15 years ahead, together with 95-percent confidence bands around that estimate. ${ }^{6}$ The persistence of the effects of many of these announcements on forward interest rates is remarkable, going out even 15 years in many cases.

The response of long-term forward rates to these releases is at odds with the predictions of the macroeconomic models considered above. Each of the data surprises included in the regressions presumably reflects some combination of the macroeconomic disturbances from that model. Thus, if one does not expect to find a sizable response of long-term interest rates to the models' shocks $\varepsilon^{\pi}$ and $\varepsilon^{y}$, then one would not expect to find such a response to the macroeconomic data releases either.

\section{B. The Sensitivity of Long-Term Interest Rates to Monetary Policy Surprises}

Forward rates in Table 1 also respond very strongly to monetary policy surprises. We measure monetary policy surprises using federal funds futures rates, which provide high-quality, virtually continuous measures of market expectations for the federal funds rate, as noted by Joel T. Krueger and Kenneth N. Kuttner (1996), Rudebusch (1998), and Allan D. Brunner (2000). ${ }^{7}$ The federal funds futures contract for a given month settles at the end of the month based on the average federal funds rate that was realized over the course of that month. Thus, daily changes in the current-month futures rate reflect revisions to the market's expectations for the federal funds rate over the remainder of the month. As explained in Kuttner (2001), the change in the current month's contract rate on the day of a Federal Open Market Committee (FOMC) announcement, once scaled up to ac-

\footnotetext{
${ }^{6}$ Note that these confidence bands do not widen at longer horizons (as they would in a VAR) because these regressions are not attempting to predict the level of the short-term rate that will be realized far in the future, but rather measure the revision to expectations for that rate that is embedded in forward rates.

${ }^{7}$ Gürkaynak et al. (2002) show that, among many financial instruments that potentially reflect expectations of monetary policy, federal funds futures are the best predictor of future policy actions.
}

count for the timing of the announcement within the month, provides a measure of the surprise component of the FOMC decision. ${ }^{8} \mathrm{We}$ compute the surprise component associated with every FOMC meeting and inter-meeting policy action by the FOMC over our sample. ${ }^{9}$ Note that these monetary policy surprises are measured in basis points rather than standard deviations.

As one would expect, forward rates at the short end of the yield curve increase following a surprise tightening of the federal funds rate (and decrease following a surprise easing). Since the federal funds rate has some persistence, as noted by many authors, tighter policy today leads to expectations that the federal funds rate will remain higher in the near future, thus pushing near-term forward rates in the same direction as the policy surprise. At longer horizons, however, forward rates actually move in the direction opposite to that of the policy surprise, i.e., a surprise policy tightening actually causes long-term forward rates to fall. This can be seen more clearly in Figure 3, which plots the response of forward rates at different horizons to a hypothetical 100-basis-point surprise monetary policy tightening. The response turns negative after about four years, and is significantly negative at horizons from nine to 15 years.

This finding stands in sharp contrast to conventional wisdom in the literature. For example, Timothy Cook and Thomas Hahn (1989) report that long-term interest rates move in the same direction as monetary policy actions, and Christina D. Romer and David H. Romer (2000) take

\footnotetext{
${ }^{8}$ In order to avoid very-large-scale factors, if the monetary policy announcement occurs in the last seven days of the month, we use the next-month contract rate instead of scaling up the current-month contract rate.

${ }^{9}$ Since 1994, the FOMC has explicitly announced its target for the federal funds rate on the afternoon of the FOMC meeting. Prior to 1994, the FOMC implicitly announced its target to financial markets through the size and type of open-market operation the following morning. We take into account this change in timing pre- and post-1994 (as well as some exceptions to these rules) in computing our monetary policy surprises. We exclude the post-9/11 intermeeting ease on September 17, 2001, and the eight monetary policy surprises from 1990 to 1994 that took place on the day of (and as an endogenous response to) an employment report. Rudebusch (1998) and Gürkaynak et al. (2005) discuss the importance of this last issue.
} 


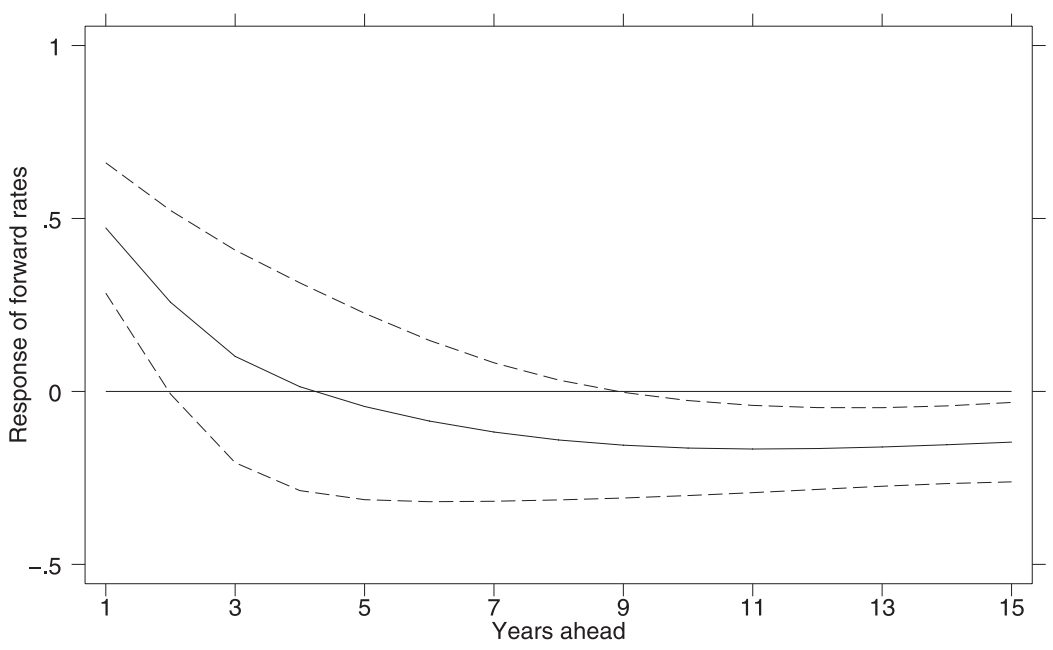

Figure 3. Response of Forward Rates to Monetary Policy Surprises

this empirical "fact" as given and offer an explanation for this "anomalous" behavior. The primary difference between these earlier authors' results and ours is that they consider long-term yields - which are influenced by the positive response of near-term forward ratesinstead of long-term forward rates. It should also be noted that these earlier authors' measures of monetary policy surprises suffer from measurement error, since they use only the raw change in the federal funds rate target, effectively treating each policy action by the FOMC as having been completely unexpected by the markets. ${ }^{10}$

As with macroeconomic data releases, our findings for monetary policy surprises are inconsistent with the economic models considered above, which would view monetary policy shocks (corresponding to the shock term $\varepsilon_{t}^{i}$ in the model) as transitory movements away from the steady state that warrant no response of long-term forward rates (see Figure 1). Moreover, the fact that monetary policy surprises cause long-term forward rates to move in the direction opposite to short-term rates-in contrast to the surprises in all of our macroeco-

\footnotetext{
${ }^{10}$ Kuttner (2001) shows that, not surprisingly, it is the surprise component of monetary policy decisions that are related to movements in the yield curve, rather than the raw monetary policy actions themselves.
}

nomic data releases-suggests a very natural explanation for the source of these movements.

\section{A Possible Explanation for the Behavior of Long-Term Rates: Changes in $\pi^{*}$}

By Fisher's equation, the steady-state shortterm nominal interest rate $i^{*}$ approximately equals the steady-state real interest rate $r^{*}$ plus the steady-state level of inflation $\pi^{*}$ :

$$
i^{*}=r^{*}+\pi^{*} .
$$

Standard asset-pricing theory implies that forward rates at sufficiently long horizons equal the expected steady-state short-term rate $i *$ plus a risk premium $\rho$. Since we have shown that very-long-horizon forward rates respond to many macroeconomic and monetary policy surprises, it follows that one (or more) of $r^{*}, \pi^{*}$, and $\rho$ are changing in response to these surprises.

We first show that time variation in the private sector's estimate of the steady-state rate of inflation, $\pi^{*}$, is consistent with all of our findings. We then provide evidence that suggests that changes in $r^{*}$ or $\rho$, by themselves, are generally not sufficient to explain all of our empirical results, so that one must rely at least 
partly on changes in the private sector's perception of $\pi^{*}$.

To show this, we augment the baseline model of Section I to allow the private sector's estimate of the long-run level of inflation to vary over time. Rather than assuming some kind of irrational or erroneous behavior on the part of the private sector, we assume that the central bank's target for inflation $\pi^{*}$ really does vary over time. In particular, we allow $\pi^{*}$ to have some (small) dependence on past values of $\pi$, as follows:

$$
\pi_{t}^{*}=\pi_{t-1}^{*}+\theta\left(\bar{\pi}_{t-1}-\pi_{t-1}^{*}\right)+\varepsilon_{t}^{\pi^{*}}
$$

where $\bar{\pi}_{t-1}$ is the trailing four-quarter moving average of inflation and $\varepsilon_{t}^{\pi^{*}}$ captures any exogenous changes to the central bank's inflation target. Under this specification, inflation below the current $\pi^{*}$ will tend to decrease the central bank's inflation target, and inflation above the current $\pi^{*}$ will tend to raise it. Note that the model in Section I is a special case of this, with $\pi^{*}$ observed and constant (i.e., $\theta$ equal to zero and $\varepsilon_{t}^{\pi^{*}}$ always zero).

We do not take a stand on why the central bank might behave in this way, but simply note that this equation seems to capture some features of the Federal Reserve's behavior over our sample. ${ }^{11}$ We also emphasize that we regard equation (4) as only an approximation of the Fed's behavior over our sample-a period during which inflation remained within a fairly low range. Clearly, the Fed would not tolerate inflation that was either well above or well below this range, and so equation (4) would become invalid if $\pi^{*}$ ever began to move very far away from the low levels of inflation observed over our sample.

We assume that the central bank's inflation $\operatorname{target} \pi^{*}$ is not directly observed by the private

\footnotetext{
${ }^{11}$ One possibility is that the costs of driving inflation all the way back to its original $\pi^{*}$ after a shock are, for some reason, larger than the benefits. Alternatively, private agents' long-run expectation of inflation may drift over time, and the central bank perceives that small changes in the steady-state rate of inflation are less costly than trying to change the public's expectations. Equation (4) also has some similarities to "opportunistic disinflation," discussed in Athanasios Orphanides and David Wilcox (1996).
}

sector, and thus must be inferred by agents on the basis of the central bank's actions, as in Sharon Kozicki and Peter Tinsley (2001b), Tore Ellingsen and Ulf Soderstrom (2001), and Christopher Erceg and Andrew Levin (2003). Private agents update their estimate of the central bank's inflation target, denoted $\hat{\pi}_{t}^{*}$, by Kalman filtering. ${ }^{12}$ In particular, agents observe the deviation of the interest rate $i_{t}$ from their prior expectation $\hat{l}_{t}$, where $\hat{l}_{t}$ is determined from their knowledge of equation (3), and they revise $\hat{\pi}_{t}^{*}$ by an amount determined by the Kalman gain parameter $\kappa$ as follows:

$$
\hat{\pi}_{t}^{*}=\hat{\pi}_{t-1}^{*}+\theta\left(\bar{\pi}_{t-1}-\hat{\pi}_{t-1}^{*}\right)-\kappa\left(i_{t}-\hat{\imath}_{t}\right) .
$$

We then simulate the impulse responses of the model defined by equations (1) through (5) using exactly the same parameter values as before, and choosing values for $\theta$ and $\kappa$ to match roughly the estimated responses of long-term forward rates in our data. ${ }^{13}$ It turns out that we require only very modest values for $\theta$ (the dependence of the central bank's inflation target on recent inflation) to match our term structure evidence. In particular, values of $\theta=0.02$ and $\kappa=0.1$ match the data very well.

Figure 4 presents these impulse responses using the parameters estimated by Rudebusch and the values $\theta=0.02$ and $\kappa=0.1$. The qualitative features of our empirical findings are reproduced very nicely. For example, after an inflation shock (the first column), the short-term nominal interest rate rises gradually, peaks after a few years, and then returns to a long-run steady-state level that is about 35 basis points higher than the original steady state. This is due

\footnotetext{
${ }^{12}$ This procedure is optimal under the assumptions of normally distributed shocks and a normally distributed prior for the inflation target; for other shock distributions, the Kalman filter is the optimal linear inference procedure. For simplicity, we assume that equations (1) through (5), all parameter values, and the output and inflation shocks $\varepsilon^{\pi}$ and $\varepsilon^{y}$ are perfectly observed by the private sector, so that only $\pi^{*}, \varepsilon^{i}$, and $\varepsilon^{\pi^{*}}$ are unobserved.

${ }_{13}$ Alternatively, one could reestimate all the parameters of the model jointly, but our intentions here are only to illustrate the general properties of the model. Reestimating all the parameters would also limit the comparability of the results to those shown in Figure 1.
} 

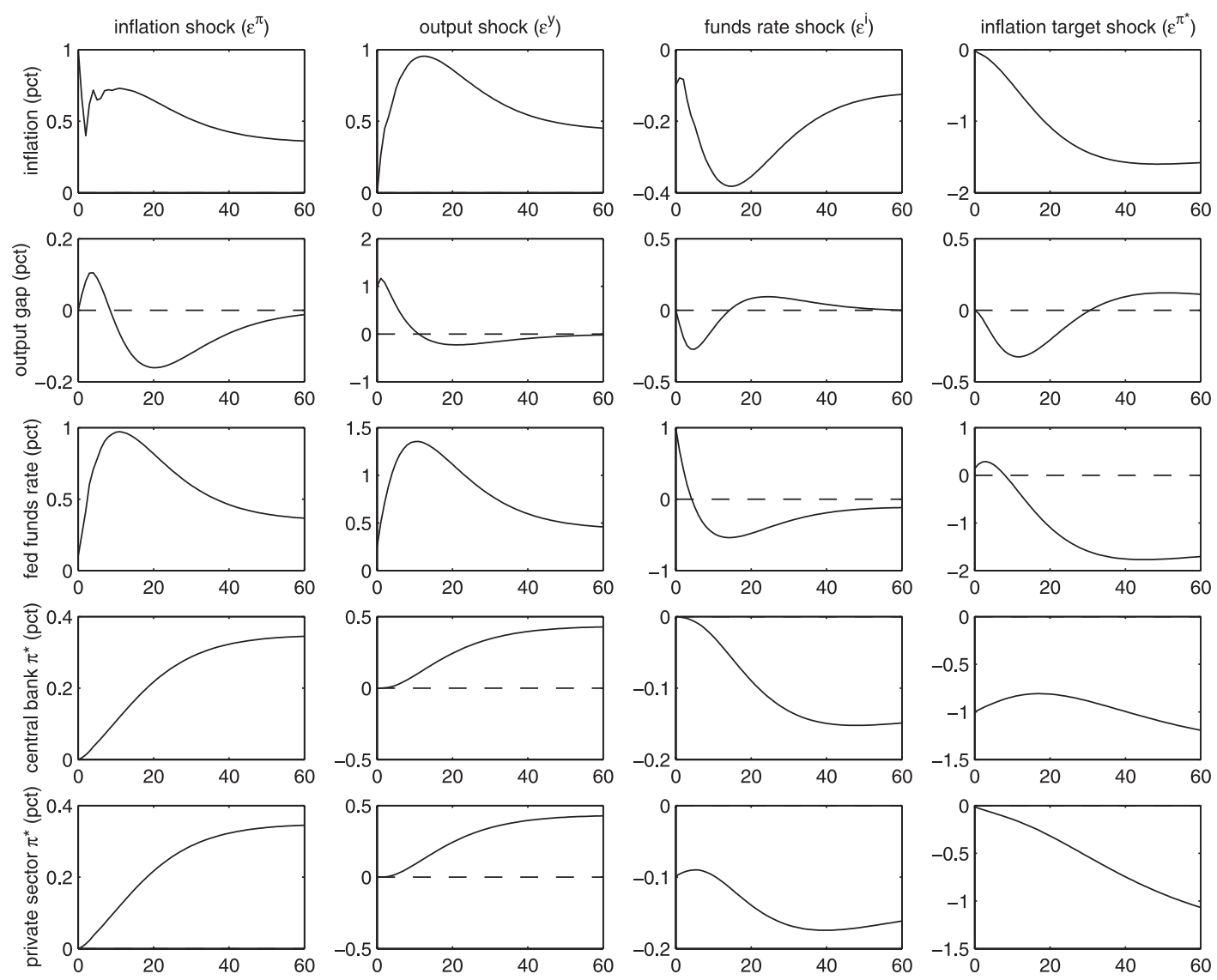

Figure 4. Interest Rate Impulse Responses for Models with Time-Varying $\pi^{*}$

(Rudebusch Model)

to the fact that the higher levels of inflation on the transition path lead the central bank's target $\pi^{*}$ to rise somewhat as a result. A similar response of short-term nominal interest rates and inflation can be seen in response to a 1percent shock to output (the second column).

For the transitory short-term interest rate shock (the third column), two effects are present. First, when the private sector sees the surprise tightening in short-term interest rates, they respond by partially revising downward their estimate of the central bank's target $\pi^{*}$. Second, as inflation in the economy falls in response to both the monetary tightening and the fall in expectations of inflation, the central bank's target $\pi^{*}$ begins to fall as well. In the long run, the short-term nominal interest rate and inflation return to lower levels than where they began.

The fourth column of Figure 4 depicts an exogenous 1-percent reduction in the central bank's inflation target. The private sector gradually revises its estimate of $\pi^{*}$ downward as it learns about the change; in the end, inflation and the short-term nominal interest rate are significantly lower than their original steady-state values.

Thus, this simple modification to the baseline model can account for all of the patterns of forward rates we see in the data. Positive macroeconomic surprises lead to expectations of higher steady-state nominal interest rates, inducing a positive response in long-term forward rates. Surprise monetary policy tightening 
(which might be some combination of the last two shocks in the model) cause the steady-state short-term interest rate to end up lower than just before the policy action, inducing a negative response of far-ahead forward rates to the shock. ${ }^{14}$

Although changes in $\pi^{*}$ can account for our empirical findings, it is worth considering whether there are other possible explanations. The steady-state real interest rate $r^{*}$ might vary over time, but such changes alone do not appear sufficient to explain our term structure evidence. For example, it is hard to see why financial markets would revise $u p$ their estimate of $r^{*}$ following a surprise increase in inflation (the CPI or PPI), or why financial markets would modify their estimate of $r^{*}$ in response to monetary policy surprises. ${ }^{15}$

Changes in risk premia $\rho$ are more difficult to rule out, because they are so poorly understood. Nonetheless, if changes in risk premia are in fact responsible for our empirical findings, then these changes are mimicking very closely the effects of changes in $\pi^{*}$. Indeed, we cannot rule out that these changes are due to changes in an "inflation risk premium." Distinguishing between changes in the inflation risk premium and changes in the long-run expected rate of inflation is inherently difficult, ${ }^{16}$ but the exact breakdown between mean inflation and inflation risk is of secondary concern for our main conclusion-that it is financial market concerns about long-term inflation that seems to explain the behavior of long-term interest rates in re-

\footnotetext{
${ }^{14}$ Note that learning and imperfect information about the central bank's target play a role only in the third and fourth columns of Figure 4, and not in the first two columns. Thus, a model based solely on learning or imperfect credibility (as in Kozicki and Tinsley, 2001a, b; or Erceg and Levin, 2003) would not be able to explain all of our empirical results.

${ }^{15}$ In the working paper (Gürkaynak et al., 2003), we show that forward rates derived from inflation-indexed Treasury Inflation-Protected Securities (TIPS) do not respond to macroeconomic and monetary policy surprises, which also suggests that changes in $r^{*}$ are not the major explanation for our findings.

${ }^{16}$ Note that in the models from Section I, the entire distribution of inflation outcomes at long enough horizons is unaffected by current shocks. Thus, one might think that, if inflation expectations were perfectly anchored, then any risk premium associated with inflation in long-horizon forward rates would be relatively small and unresponsive to current shocks.
}

sponse to macroeconomic and monetary policy surprises.

One piece of evidence that does suggest that expectations of long-run inflation in the United States are not strongly anchored is survey data. For example, the median ten-year CPI inflation forecast in the Federal Reserve Bank of Philadelphia's Survey of Professional Forecasters has fallen from 4 percent in the fourth quarter of 1991 (the first time the long-run forecast question was asked) to a little under 2.5 percent by the end of 2002. This decline of about 1.5 percentage points compares with a fall of about 2.5 percentage points in one-year forward interest rates ending ten years ahead over the same period, and matches closely the declines that one sees in other survey measures, such as the Michigan Survey and the longer-term inflation projections published by the Congressional Budget Office. Indeed, the CBO explicitly states that their medium-term inflation expectation is based on their beliefs about the Federal Reserve's desired inflation level (CBO 2003, p. 46).

\section{Conclusions}

This paper has presented evidence that forward rates at long horizons react significantly to a variety of macroeconomic and monetary policy surprises that would be expected to have only transitory effects on the short-term interest rate under standard macroeconomic models. In particular, the empirical evidence is at odds with the modeling assumption that the long-run properties of the economy are constant and perfectly known by all agents. We argue that the most plausible explanation for the observed term structure behavior is that the private sector has adjusted its expectations of the long-run level of inflation in response to these macroeconomic and monetary policy surprises.

This conclusion has potentially important implications for macroeconomic models themselves. Not only would those models have difficulty capturing the long-run behavior of the economy, but any misspecification of those long-run properties could alter the short-run structural behavior of the models as well. In particular, the models considered are calibrated to match the dynamics of inflation at business cycle frequencies, under the assumption that 
long-run inflation expectations are perfectly anchored. To the extent that this assumption is violated, the short-run dynamics of inflation would be misspecified, and estimates of the parameters governing those dynamics would be incorrect.

Our findings may also have important implications for the conduct of monetary policy. Although our results suggest that inflation expectations in the United States have responded to macroeconomic and monetary policy surprises, the Federal Reserve has achieved remarkable economic performance over our sample period, with inflation expectations falling to very low levels. Nevertheless, to the extent that there may be benefits to stabilizing long-run forward rates and inflation expectations, our results suggest that there is some scope for improvement. In that regard, credibly committing to an explicit inflation target could help stabilize long-term forward rates and inflation expectations.

\section{REFERENCES}

Brunner, Allan D. "On the Derivation of Monetary Policy Shocks: Should We Throw the VAR Out with the Bath Water?" Journal of Money, Credit, and Banking, 2000, 32(2), pp. 254-79.

Clarida, Richard; Gali, Jordi and Gertler, Mark. "Monetary Policy Rules and Macroeconomic Stability: Evidence and Some Theory." Quarterly Journal of Economics, 2000, 115(1), pp. 147-80.

Congressional Budget Office. "The Budget and Economic Outlook: Fiscal Years 20042013," Washington, DC: U.S. Government Printing Office, 2003.

Cook, Timothy and Hahn, Thomas. "The Effect of Changes in the Federal Funds Rate Target on Market Interest Rates in the 1970s." Journal of Monetary Economics, 1989, 24(3), pp. 331-51.

Ellingsen, Tore and Soderstrom, Ulf. "Monetary Policy and Market Interest Rates." American Economic Review, 2001, 91(5), pp. 15941607.

Erceg, Christopher J. and Levin, Andrew T. "Imperfect Credibility and Inflation Persistence." Journal of Monetary Economics, 2003, 50(4), pp. 915-44.
Estrella, Arturo and Fuhrer, Jeffrey C. "Dynamic Inconsistencies: Counterfactual Implications of a Class of Rational-Expectations Models." American Economic Review, 2002, 92(4), pp. 1013-28.

Fleming, Michael and Remolona, Eli. "What Moves the Bond Market?" Federal Reserve Bank of New York economic policy review, 1997, 3(4), pp. 31-50.

Fuhrer, Jeffrey C. "The (Un)Importance of Forward-Looking Behavior in Price Specifications." Journal of Money, Credit, and Banking, 1997, 29(3), pp. 338-50.

Gürkaynak, Refet S.; Sack, Brian and Swanson, Eric. "Market-Based Measures of Monetary Policy Expectations." Federal Reserve Board, Finance and Economics Discussion Series: Working Paper No. 2002-40, 2002.

Gürkaynak, Refet S.; Sack, Brian and Swanson, Eric. "The Excess Sensitivity of Long-Term Interest Rates: Evidence and Implications for Macroeconomic Models." Federal Reserve Board, Finance and Economics Discussion Series: Working Paper No. 2003-50, 2003.

Gürkaynak, Refet S.; Sack, Brian and Swanson, Eric. "Do Actions Speak Louder than Words? The Response of Asset Prices to Monetary Policy Actions and Statements." International Journal of Central Banking, forthcoming, 2005.

Kozicki, Sharon and Tinsley, P. A. "Shifting Endpoints in the Term Structure of Interest Rates." Journal of Monetary Economics, 2001a, 47(3), pp. 613-52.

Kozicki, Sharon and Tinsley, P. A. "What Do You Expect? Imperfect Policy Credibility and Tests of the Expectations Hypothesis." Federal Reserve Bank of Kansas City, Research Working Paper: RWP 01-02, $2001 b$.

Krueger, Joel T. and Kuttner, Kenneth N. "The Fed Funds Futures Rate as a Predictor of Federal Reserve Policy," Journal of Futures Markets, 1996, 16(8), pp. 865-79.

Kuttner, Kenneth N. "Monetary Policy Surprises and Interest Rates: Evidence from the Fed Funds Futures Market." Journal of Monetary Economics, 2001, 47(3), pp. 523-44.

Orphanides, Athanasios and Wilcox, David W. "The Opportunistic Approach to Disinflation." Federal Reserve Board, Finance and Economics Discussion Series: No. 96-24, 1996. 
Roberts, John M. "Is Inflation Sticky?" Journal of Monetary Economics, 1997, 39 (2), pp. 173-96.

Romer, Christina D. and Romer, David H. "Federal Reserve Information and the Behavior of Interest Rates." American Economic Review, 2000, 90(3), pp. 429-57.

Rudebusch, Glenn D. "Do Measures of Monetary Policy in a VAR Make Sense?" International Economic Review, 1998, 39(4), pp. 907-31.

Rudebusch, Glenn D. "Is the Fed Too Timid?
Monetary Policy in an Uncertain World." Review of Economics and Statistics, 2001, 83(2), pp. 203-17.

Rudebusch, Glenn D. “Term Structure Evidence on Interest Rate Smoothing and Monetary Policy Inertia." Journal of Monetary Economics, 2002, 49(6), pp. 1161-87.

Svensson, Lars E. O. "Estimating and Interpreting Forward Interest Rates: Sweden 1992-1994." Center for Economic Policy Research, CEPR Discussion Papers: No. 1051, 1994. 